\title{
Effects of Alkaline Treatment on the Mechanical and Rheological Properties of Low-Density Polyethylene/Spartium junceum Flour Composites
}

\author{
S. Ikhlef, S. Nekkaa, M. Guessoum, and N. Haddaoui \\ Laboratoire Physico-Chimie des Hauts Polymères, Département de Génie des Procédés, Faculté de Technologie, \\ Université Ferhat Abbas, Sétif 19000, Algeria \\ Correspondence should be addressed to S. Nekkaa, s_nekkaa@yahoo.fr
}

Received 12 September 2012; Accepted 15 October 2012

Academic Editors: Y. Habibi and A. Uygun

Copyright $\odot 2012$ S. Ikhlef et al. This is an open access article distributed under the Creative Commons Attribution License, which permits unrestricted use, distribution, and reproduction in any medium, provided the original work is properly cited.

The effects of Spartium junceum (SJ) flour content, treatment time, and temperature on the mechanical and rheological properties of low density polyethylene/Spartium junceum flour (LDPE/SJ) composites were studied. SJ flour was treated with $\mathrm{NaOH}$ (5\% wt) for 24,48 , and $72 \mathrm{~h}$ at $25^{\circ} \mathrm{C}$ and $40^{\circ} \mathrm{C}$. FTIR results showed that there is a partial removal of lignin and hemicelluloses after treatment which improved the interfacial adhesion matrix/SJ flour. Also, the alkaline treatment improved notably the tensile strength and Young's modulus and increased slightly the elongation at break of LDPE/SJ composites compared to those with untreated flour.

\section{Introduction}

Natural organic fibers from renewable natural resources offer the potential to act as biodegradable reinforcing materials as an alternative for the use of glass or carbon fiber and inorganic fillers $[1,2]$. These fibers offer several advantages including high specific strength and modulus, low cost, low-density, renewable nature, biodegradability, absence of associated health hazards, easy fiber surface modification, and wide availability [3]. But, the main drawbacks of such composites are their water sensitivity, their relatively poor dimensional stability, the changing of fiber characteristics with origin, poor adhesion to basically all matrix polymers, and poor processability at high fiber contents.

Much work has been done on virgin thermoplastic and natural fiber composites, which have successfully proven their applicability to various fields of technical applications, especially for load-bearing application. Indeed, thermoplastics, such as polyethylene (PE) $[4,5]$, polypropylene (PP) [69], polyvinyl chloride (PVC) [10], and polystyrene (PS) [11], have been compounded with natural fibers (such as wood, kenaf, flax, hemp, cotton, sisal, jute, abaca, etc.) to prepare composites.
Nekkaa et al. [12] reported that the use of silane Z-6020 for SJ fibers modification improves the dynamic mechanical properties of PP/SJ fibers composites. Also, the results of water absorption showed that silane treatment reduced the water absorption capacity compared to untreated composites. The absorption of water by PP/SJ fibers composites approaches the kinetics of a Fickian diffusion case I at ambient temperature [13]. The alkaline treatment is also another method to treat vegetable fibers to increase the contact fiber matrix and thus their adhesion to each other.

So, the aim of this work is to study the effects of untreated and treated Spartium junceum flour content as well as the time and the temperature of flour surface modification on the mechanical and rheological properties of LDPE/SJ flour composites materials.

\section{Experimental}

2.1. Materials. The polymer matrix used in this study was low-density polyethylene (LDPE) "B-21," having a density of $920 \mathrm{~kg} / \mathrm{m}^{3}$ and a melt flow index (MFI) experimentally determined $\left(1,51 \mathrm{~g} / 10 \mathrm{~min}\right.$ at $\left.190^{\circ} \mathrm{C}\right)$. 
Spartium junceum flour was prepared in our laboratory from fibers obtained from local sources. The shurb can be cultivated manually, and then the fiber was cleaned and crushed. The dimension average particle size was $100 \mu \mathrm{m}$.

2.2. Treatment of Spartium junceum Flour. The flour was treated with sodium hydroxide $(\mathrm{NaOH})$ aqueous solution $(5 \% \mathrm{w} / \mathrm{v})$ for 24,48 , and $72 \mathrm{~h}$ at two different temperatures: $25^{\circ} \mathrm{C}$ and $40^{\circ} \mathrm{C}$. Then, it was washed with distilled water until all the sodium hydroxide was eliminated, and the washing water $\mathrm{pH}$ was neutral. Subsequently, flour was dried at $60^{\circ} \mathrm{C}$ until constant weight was found.

2.3. Compounding and Processing. The composite materials LDPE/SJ were prepared by mixing the polymer matrix and the flour in a two-roll mixer (Busto Arsizio) at a temperature of $158^{\circ} \mathrm{C}$ and a mixing rate of $32 \mathrm{rpm} / \mathrm{min}$ for 10 min. Different composites LDPE/SJ flour were prepared; the pretreated and treated SJ flour amounts added were 10, 20 , and $30 \mathrm{wt} \%$.

\subsection{Measurements Characterization Methods}

2.4.1. FTIR Spectroscopy. The spectrometer, FTIR-8400SShimadzu, was used in the transmission mode with a resolution of $2 \mathrm{~cm}^{-1}$ in the range of $4500-500 \mathrm{~cm}^{-1}$. The samples were tested after being pressed with $2.5 \mathrm{wt} \%$ of $\mathrm{KBr}$ to form a disc.

2.4.2. Tensile Test. Specimens tensile test was conducted at $23 \pm 2^{\circ} \mathrm{C}$ using a universal testing machine (Zwick Postfash 4350 ) with a crosshead speed of $5 \mathrm{~mm} / \mathrm{min}$ according to ISO 527-3 standard. Five specimens of each composition were tested, and the average value reported.

The tensile properties (Young's modulus E, tensile strength $\sigma_{r}$, and elongation at break $\varepsilon_{r}$ ) are evaluated from the stress-strain curves.

2.4.3. Impact Strength. Izod and Charpy impact measurements were carried out with a Ceast Resil Impact instrument in accordance with EN ISO 180 standard at $23 \pm 2^{\circ} \mathrm{C}$. The capacity of the pendulum is $7.5 \mathrm{Kg}$. The impact strength of unnotched specimens $\left(a_{n}\right)$ and the impact strength of notched specimens $\left(a_{k}\right)$ were calculated.

2.4.4. Hardness. Shore D hardness of the samples was evaluated by using a hardness tester. Samples were placed on a horizontal surface. Tester was kept in vertical position and pressed on the specimen so that the presser foot was parallel to specimen. Five readings at different points were noted, and average value is reported according to NF EN ISO 868 standard.

2.4.5. Differential Scanning Calorimetry Studies. A differential scanning calorimeter (NETZSCH.DSC 200 PC) was used. The heating rate was $10^{\circ} \mathrm{C}$ per min, and the temperature

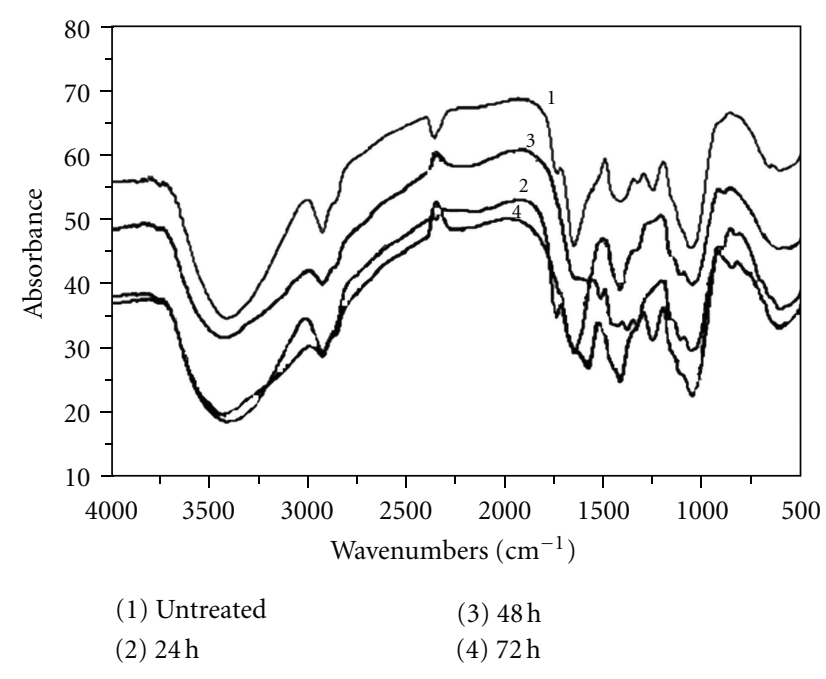

FIGURE 1: FTIR spectra of Spartium junceum flour untreated and treated with $\mathrm{NaOH}$ at different times at $25^{\circ} \mathrm{C}$.

ranged from $20^{\circ} \mathrm{C}$ to $220^{\circ} \mathrm{C}$. A value of $\Delta H_{\infty}$ equal to $280 \mathrm{~J} / \mathrm{g}$ for a pure crystalline LDPE is used [14].

Enthalpies of fusion $\Delta H_{m}$ were evaluated from the peak area of fusion. The crystallinity $X_{c}$ is then determined by the following relationship:

$$
X_{c}(\%)=\frac{\Delta H_{m}}{\Delta H_{\infty}} \cdot 100,
$$

$X_{c}(\%)$ is degree of crystallinity; $\Delta H_{m}$ is experimental enthalpy of fusion; $\Delta H_{\infty}$ is Enthalpy of fusion of a $100 \%$ LDPE cristalline sample.

\section{Results and Discussions}

3.1. FTIR Spectroscopy. Figure 1 shows the FTIR spectra of untreated and alkaline treated Spartium junceum flour for different times of treatment at $25^{\circ} \mathrm{C}$.

The intensity of 3400 and $1052 \mathrm{~cm}^{-1}$ peaks assigned to the stretching vibrations of hydroxyl groups of cellulose and C-O groups of hemicelluloses [15], respectively, decreased with the chemical treatment of the filler. The alkaline treatment of the SJ flour induces the partial removal of hemicellulose and lignin, because of the disappearance of the band characterizing the carbonyl group observed at $1737 \mathrm{~cm}^{-1}$ [16]. The peak at $1644 \mathrm{~cm}^{-1}$ in the untreated SJ flour is associated with the adsorbed water. The decrease in this peak intensity in the chemically treated SJ flour is due to the partial removal of hemicelluloses. The weak peak noticed between 1423 and $1412 \mathrm{~cm}^{-1}$ is assigned to the in plane bending deformation of $-\mathrm{CH}_{2}$ of lignin. The stretching vibrations of $\mathrm{C}=\mathrm{C}$ bonds in aromatic rings of lignin are observed at approximately 1577 and $1507 \mathrm{~cm}^{-1}$ [17]. The sharp peak observed at $2926 \mathrm{~cm}^{-1}$ reflects $\mathrm{C}-\mathrm{H}$ asymmetric deformation of lignin. In conclusion, the alkaline treatment changes the supermolecular structure of flour while the chemical structure is not significantly affected. Due to the intra- and interfibrillar swelling, the accessibility of flour changes drastically. 


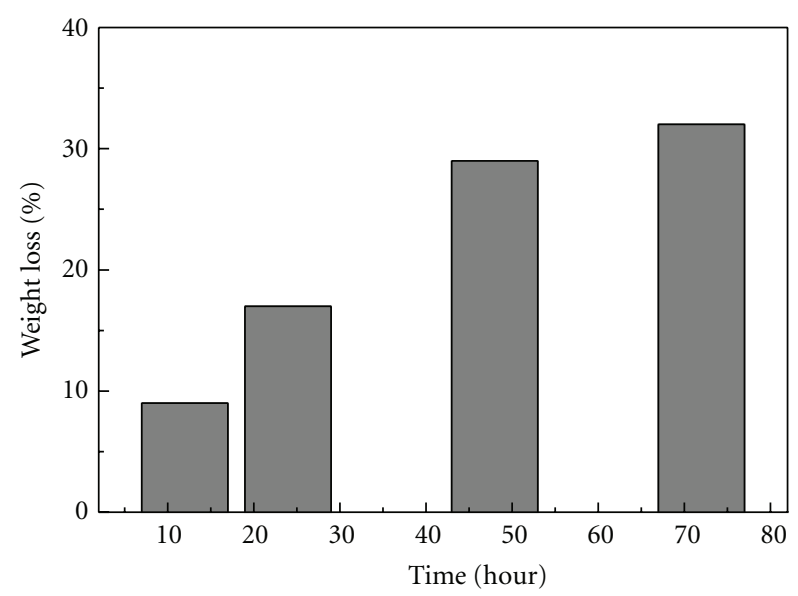

Figure 2: Influence of time of treatment at $25^{\circ} \mathrm{C}$ on the percentage of weight loss flour.

The possible chemical reaction between the alkaline solution and the hydroxyl groups of the SJ flour is as follows:

$$
\text { Fiber-OH }+\mathrm{Na}-\mathrm{OH} \longrightarrow \text { Fiber- } \mathrm{O}^{-} \mathrm{Na}^{+}+\mathrm{H}_{2} \mathrm{O} .
$$

3.2. Weight Loss. Natural fiber contains mainly cellulose, hemicellulose, and lignin. Hemicellulose is a compound containing several molecules of sugar and substances which are soluble in water or in alkaline solution. Lignin is also soluble in alkaline solution. It is possible that some of the hemicellulose and lignin will dissolve during the treatment which will cause a decrease in the mass of SJ flour [15].

Figure 2 shows the effect of the treatment time on the percentage of weight loss of SJ flour at $25^{\circ} \mathrm{C}$. We note that the evolution of the percentage of weight loss is progressively important over the first 48 hours of treatment then begins to stabilize after a treatment period of 48 hours.

\subsection{Tensile Properties}

3.3.1. Effects of Flour's Content and Treatment. Figures 3, 4, and 5 reveal the effects of the flour content and the treatment time on the tensile strength, Young's modulus, and the elongation at break of LDPE/SJ composites. The addition of unmodified SJ flour to LDPE matrix induces a sharp decrease in the tensile strength (Figure 3). Also, the tensile strength of the composites decreased with increasing flour loading, due to the weak interfacial adhesion and the low compatibility between the hydrophilic flour and hydrophobic PE [18-20]. Moreover, a significant increase in Young's modulus with increasing SJ flour content is noticed (Figure 4). Thus, the rigidity of SJ flour, which is higher than that of the thermoplastic matrix LDPE, contributes significantly to the increase of the rigidity of the whole material. At the same time, a noticeable decrease in the elongation at break prevents the elasticity of the composite material (Figure 5). On the other hand, the weak interaction matrix/flour facilitates the separation at the interface and promotes debonding, which results in a reduced deformability [7].

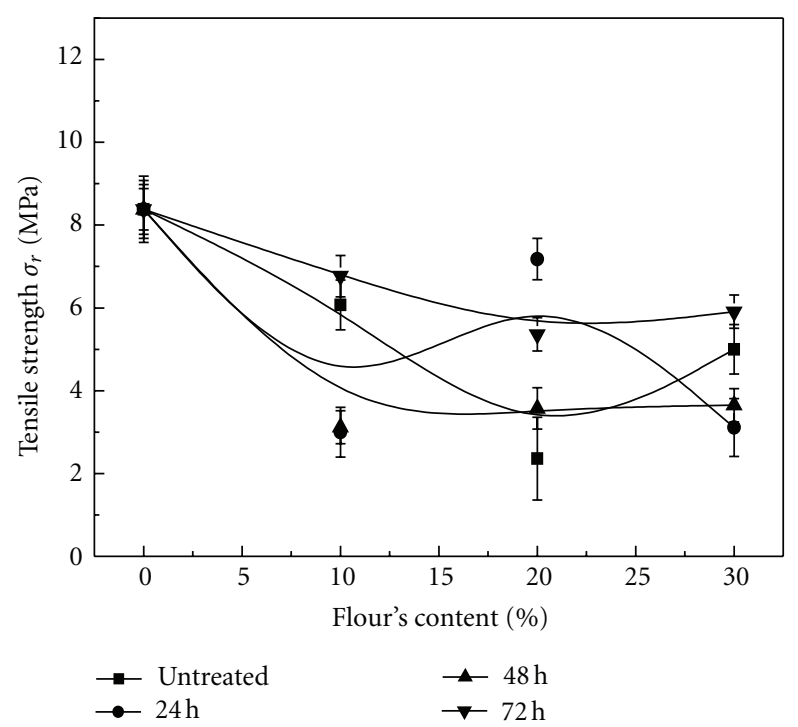

Figure 3: Effect of flour content and time of treatment at $25^{\circ} \mathrm{C}$ on the tensile strength of LDPE/SJ flour composites.

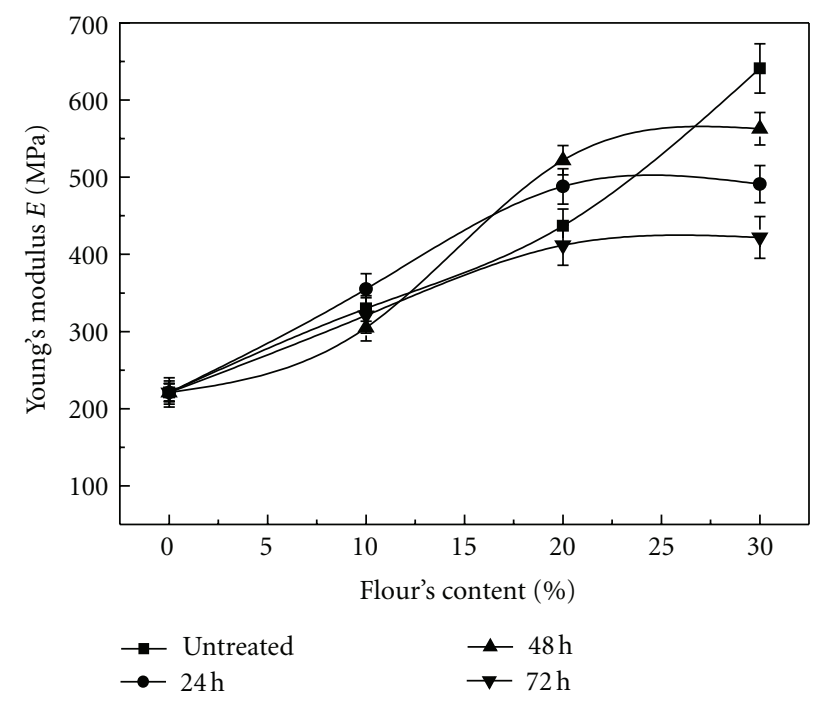

Figure 4: Effect of flour content and time of treatment at $25^{\circ} \mathrm{C}$ on the Young's modulus of LDPE/SJ flour composites.

However, the superior tensile strength of alkali-treated fabrics may be attributed to the fact that the alkaline treatment improves the adhesive characteristics of the flour surface by removing natural and artificial impurities [21]. In addition, the alkaline treatment leads to fiber fibrillation which increases the effective surface area available for contact with matrix polymer $[22,23]$.

3.3.2. Effect of Temperature. The effect of treatment temperature on the tensile properties of LDPE/SJ (70/30) composites with $\mathrm{NaOH}$-treated flour at different temperatures is shown in Table 1. In general, the values of tensile strength, Young's modulus, and the elongation at break of LDPE/SJ composites with flour treated at $25^{\circ} \mathrm{C}$ are higher than 
TABLE 1: Effect of temperature on the tensile strength, Young's modulus, and elongation at break of composites LDPE/SJ (70/30) with flour treated with $\mathrm{NaOH}$ at different times.

\begin{tabular}{|c|c|c|c|c|c|c|}
\hline \multirow{2}{*}{ Treatment time $(\mathrm{h})$} & \multicolumn{2}{|c|}{$\sigma_{r}(\mathrm{MPa})$} & \multicolumn{2}{|c|}{$E(\mathrm{MPa})$} & \multicolumn{2}{|c|}{$\varepsilon_{r}(\%)$} \\
\hline & $T\left(25^{\circ} \mathrm{C}\right)$ & $T\left(40^{\circ} \mathrm{C}\right)$ & $T\left(25^{\circ} \mathrm{C}\right)$ & $T\left(40^{\circ} \mathrm{C}\right)$ & $T\left(25^{\circ} \mathrm{C}\right)$ & $T\left(40^{\circ} \mathrm{C}\right)$ \\
\hline 24 & 6,50 & 3,75 & 491,00 & 455,00 & 7,02 & 4,69 \\
\hline 48 & 8,60 & 4,66 & 563,00 & 310,00 & 10,28 & 3,58 \\
\hline 72 & 9,43 & 8,90 & 194,00 & 325,00 & 5,12 & 4,09 \\
\hline
\end{tabular}

TABLE 2: Values of impact strength (Izod) of composites LDPE/SJ composite with treated and untreated flour.

\begin{tabular}{|c|c|c|}
\hline Composites & $a_{n}\left(\mathrm{KJ} / \mathrm{m}^{2}\right)$ & $a_{k}\left(\mathrm{KJ} / \mathrm{m}^{2}\right)$ \\
\hline LDPE/SJ $(100 / 0)$ & No break & No break \\
\hline \multicolumn{3}{|c|}{ Untreated flour } \\
\hline LDPE/SJ (90/10) & No break & 29,72 \\
\hline LDPE/SJ (80/20) & 30,67 & 17,28 \\
\hline LDPE/SJ (70/30) & 18,01 & 9,25 \\
\hline \multicolumn{3}{|c|}{ Treated flour $(24 \mathrm{~h})$} \\
\hline $\mathrm{LDPE} / \mathrm{SJ}(90 / 10) / 25^{\circ} \mathrm{C}$ & No break & No break \\
\hline $\mathrm{LDPE} / \mathrm{SJ}(80 / 20) / 25^{\circ} \mathrm{C}$ & No break & 24,59 \\
\hline $\mathrm{LDPE} / \mathrm{SJ}(70 / 30) / 25^{\circ} \mathrm{C}$ & 29,37 & 13,84 \\
\hline $\mathrm{LDPE} / \mathrm{SJ}(70 / 30) / 40^{\circ} \mathrm{C}$ & 18,86 & 9,42 \\
\hline \multicolumn{3}{|c|}{ Treated flour $(48 \mathrm{~h})$} \\
\hline $\mathrm{LDPE} / \mathrm{SJ}(90 / 10) / 25^{\circ} \mathrm{C}$ & No break & No break \\
\hline $\mathrm{LDPE} / \mathrm{SJ}(80 / 20) / 25^{\circ} \mathrm{C}$ & No break & 30,46 \\
\hline $\mathrm{LDPE} / \mathrm{SJ}(70 / 30) / 25^{\circ} \mathrm{C}$ & 27,45 & 14,38 \\
\hline $\mathrm{LDPE} / \mathrm{SJ}(70 / 30) / 40^{\circ} \mathrm{C}$ & 13,28 & 7,58 \\
\hline \multicolumn{3}{|c|}{ Treated flour $(72 \mathrm{~h})$} \\
\hline $\mathrm{LDPE} / \mathrm{SJ}(90 / 10) / 25^{\circ} \mathrm{C}$ & No break & No break \\
\hline $\mathrm{LDPE} / \mathrm{SJ}(80 / 20) / 25^{\circ} \mathrm{C}$ & No break & 21,63 \\
\hline $\mathrm{LDPE} / \mathrm{SJ}(70 / 30) / 25^{\circ} \mathrm{C}$ & 23,54 & 12,82 \\
\hline $\mathrm{LDPE} / \mathrm{SJ}(70 / 30) / 40^{\circ} \mathrm{C}$ & 18,20 & 7,94 \\
\hline
\end{tabular}

those of composites with the flour treated at $40^{\circ} \mathrm{C}$. This is undoubtedly due to the decrease in the cellulose fraction in the vegetable flour with increasing temperature, which causes depolymerization and thus the weakening of the flour, and therefore the reduction of the mechanical properties [4].

\subsection{Impact Strength}

3.4.1. Effects of Flour's Content and Treatment. The impact strength of the composites is significantly lower than of the neat polyethylene matrix (Table 2). The stiffer cellulose flour acts as stress concentrators in the polymer matrix, reducing therefore the crack initiation energy and consequently the impact strength of the composites [8]. This occurs because of the chemical incompatibility between the thermoplastic polyolefin and the polar flour, resulting in low interfacial adhesion [24].

Also, it was noticed that notched specimens showed lower resilience than unnotched ones because the energy of notched specimens presents only that of the crack propagation, while that of unnotched specimens includes the initiation and propagation of the crack.
The treatment of the flour surface shows an improvement of the impact strength of composites with treated flour compared to those with unmodified flour. The values of impact strength of the different tested composites are listed in Table 2. The treatment of the flour improves the compatibility and promotes the ability to dissipate energy during fracture.

On the other hand, processing time of 24 and 48 hours gives composites with higher values of impact strength than those of the processing time of 72 hours. This may be due to the weakening of flour; a long processing time causes a significant reduction in lignin, which weakens the flour.

3.4.2. Effect of Temperature. According to the values in Table 2, we find that the impact strength of the specimens with flour treated at $25^{\circ} \mathrm{C}$ is higher than that with the flour treated at $40^{\circ} \mathrm{C}$. This confirms the results found by the tensile test where the increase in the processing temperature of the flour causes a decrease in mechanical properties of the composite material. 


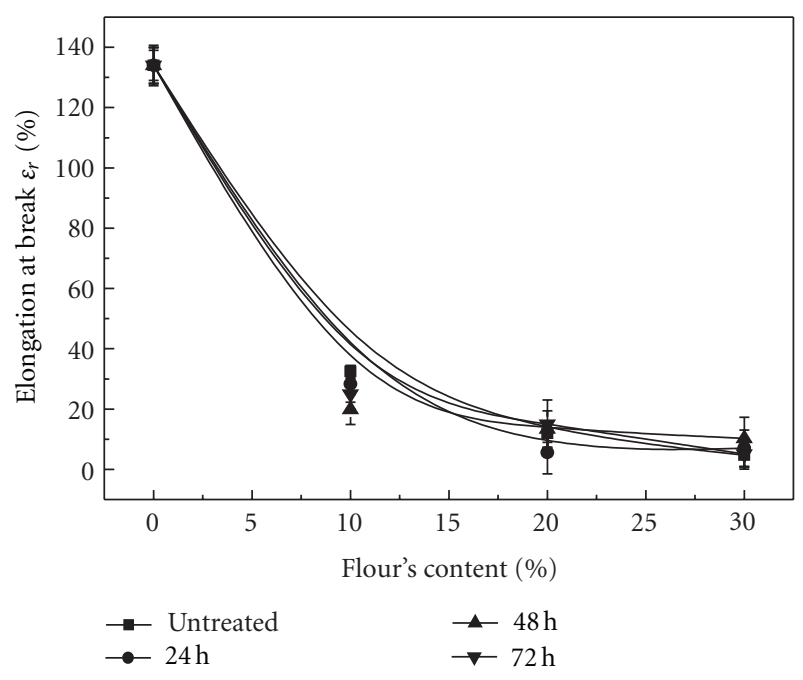

Figure 5: Effect of flour content and time of treatment at $25^{\circ} \mathrm{C}$ on the elongation at break of LDPE/SJ flour composites.

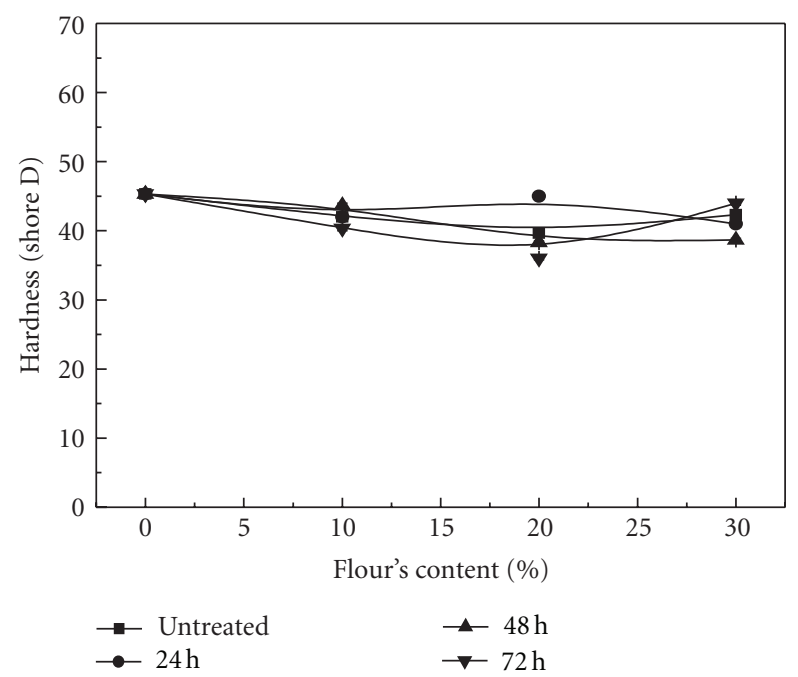

Figure 6: Effect of flour content and time of treatment at $25^{\circ} \mathrm{C}$ on the hardness of LDPE/SJ flour composites.

\subsection{Hardness Results}

3.5.1. Effect of Flour's Content and Treatment. Figure 6 shows the variations of the hardness of composites with untreated flour and $\mathrm{NaOH}$-treated flour for different times at $25^{\circ} \mathrm{C}$ as function of flour content. From the figure, we can deduce that the treatment does not significantly influence the composites hardness. This can be explained by the heterogeneity of the composite due to factors related to the flour.

\subsection{Melt Flow Index}

3.6.1. Effect of Flour's Content and Treatment. A decrease in the melt flow index with the increase of flour content

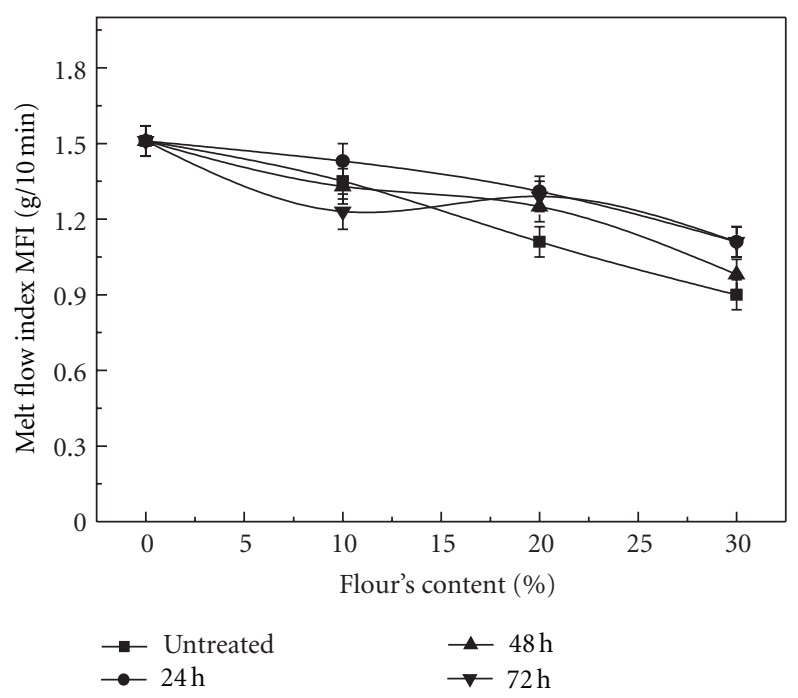

Figure 7: Effect of flour content and time of treatment at $25^{\circ} \mathrm{C}$ on the melt flow index of LDPE/SJ flour composites.

TABLE 3: Values of the melt flow index of composites LDPE/SJ (70/30) with treated flour at different times and at different temperatures.

\begin{tabular}{lcc}
\hline \multirow{2}{*}{ Treatment time $(\mathrm{h})$} & \multicolumn{2}{c}{ Melt flow index $(\mathrm{g} / 10 \mathrm{~min})$} \\
& $T\left(25^{\circ} \mathrm{C}\right)$ & $T\left(40^{\circ} \mathrm{C}\right)$ \\
\hline 24 & 1,11 & 1,23 \\
48 & 0,98 & 1,45 \\
72 & 1,11 & 1,17 \\
\hline
\end{tabular}

is reported according to Figure 7. This reflects the heterogeneity of the materials. The probability of aggregates formation increases with increasing SJ flour content. Thus aggregation depends on the composition, while the value of the maximum is determined by adhesion and the load carried by the SJ flour particles [25].

3.7. Effect of Temperature. According to Figure 7 and the values reported in Table 3 , there is a slight improvement of the composites melt flow index values after treatment, but the increasing of the process temperature does not affect the values of the melt flow index. This behavior suggests that the interfacial adhesion between the matrix and the flour is higher for modified flour, and that the level of dispersion of the flour within the polymeric matrix is also improved. The results confirm that the treatment improves the dispersion and the interfacial adhesion with the matrix.

\subsection{Differential Scanning Calorimetry Studies}

3.8.1. Effect of Flour's Content and Treatment. Figure 8 shows the thermograms of LDPE/untreated Spartium junceum flour composites. The incorporation of untreated Spartium junceum flour to the polymeric matrix has no significant impact neither on the melting temperature nor on the shape of the melting peak. These results are in agreement with those 
TABLE 4: Thermal Properties of LDPE/untreated and treated Spartium junceum flour composites.

\begin{tabular}{|c|c|c|c|c|}
\hline Samples & $T_{m}\left({ }^{\circ} \mathrm{C}\right)$ first scan & $T_{f}\left({ }^{\circ} \mathrm{C}\right)$ second scan & $\Delta H_{m}(\mathrm{~J} / \mathrm{g})$ & $X_{c}(\%)$ \\
\hline LDPE & 113,00 & 112,50 & 91,07 & 32,52 \\
\hline LDPE/SJ (90/10) & 113,00 & 112,70 & 104,14 & 37,19 \\
\hline LDPE/SJ (80/20) & 112,50 & 112,30 & 112,2 & 40,07 \\
\hline LDPE/SJ $(70 / 30)$ & 113,50 & 112,30 & 132,14 & 47,19 \\
\hline LDPE/SJ $(70 / 30)$ treated at $25^{\circ} \mathrm{C}, 24 \mathrm{~h}$ & 112,50 & 113,30 & 131,80 & 46,76 \\
\hline LDPE/SJ $(70 / 30)$ treated at $25^{\circ} \mathrm{C}, 48 \mathrm{~h}$ & 112,50 & 113,30 & 135,60 & 48,42 \\
\hline LDPE/SJ $(70 / 30)$ treated at $25^{\circ} \mathrm{C}, 72 \mathrm{~h}$ & 112,50 & 113,30 & 132,87 & 47,45 \\
\hline
\end{tabular}

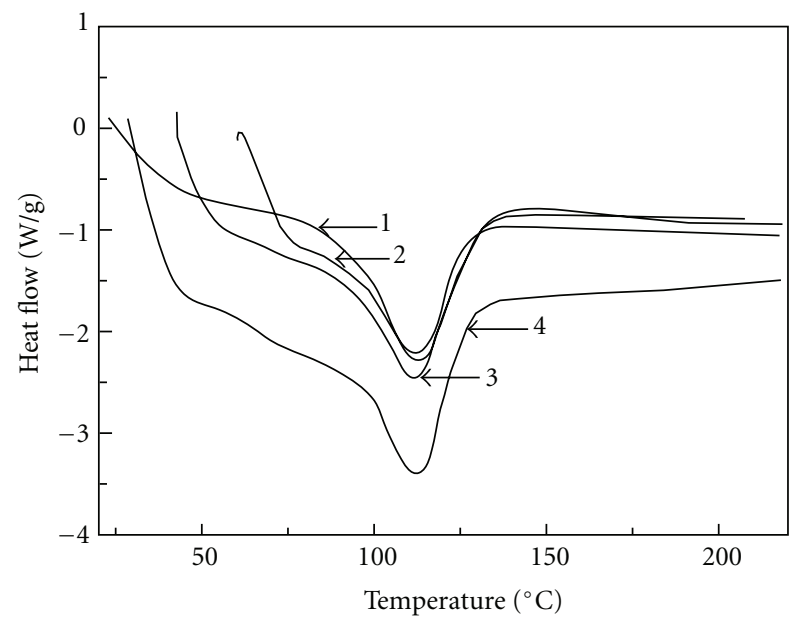

(1) LDPE

(2) LDPE/SJ flour (90/10)

(3) LDPE/SJ flour (80/20)

(4) LDPE/SJ flour (70/30)

FIGURE 8: DSC thermograms of LDPE and different LDPE samples filled with untreated Spartium junceum flour.

presented by Bendahou et al. [26], Avérous et al. [27], and Le Digabel et al. [28].

According to Table 4 , it is clear that the crystallinity $\chi_{c}$ increases with untreated flour loading. Thus, the cellulosic filler acts as nucleation sites which alter the kinetics of crystallization of the semicrystalline polymer. These results agree with those found by Joseph et al. [29] who noticed a slight increase of the crystallinity of $\mathrm{PP} /$ sisal fibers composites with increasing the fiber content. Also Nekkaa et al. [30] showed that the incorporation of SJ fiber in PP caused an apparent increase in the crystallinity.

Figure 9 shows the comparison of DSC thermograms of 70/30 LDPE/SJ composites based on the flour treated with $\mathrm{NaOH}$ at $25^{\circ} \mathrm{C}$ at different times. According to the last figure and the values reported in the Table 4, we notice that the processing time has no effect on the composites-melting temperature and crystallinity.

\section{Conclusion}

The SJ flour surface treated with alkaline treatment improved notably the tensile strength, Young's modulus, and the impact strength but slightly the elongation at break of the

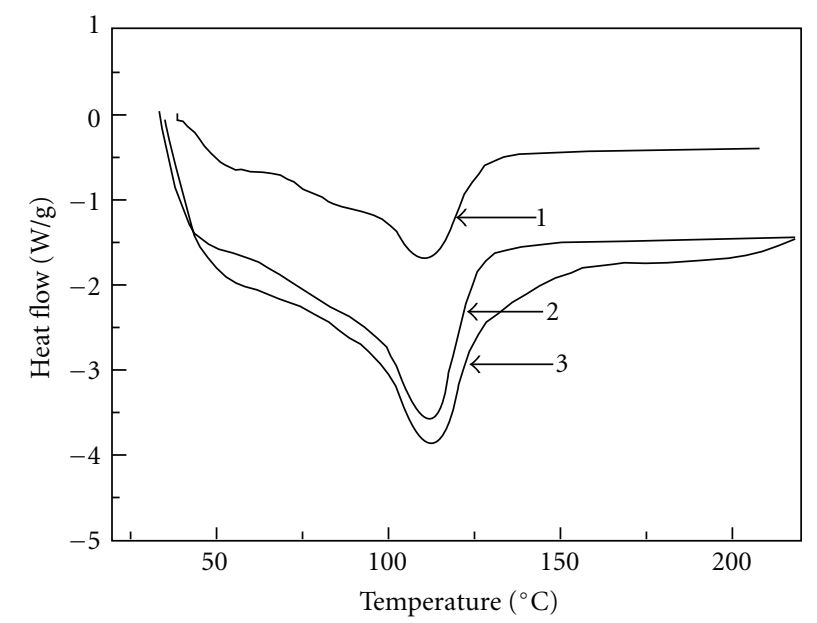
(1) $24 \mathrm{~h}$
(2) $48 \mathrm{~h}$
(3) $72 \mathrm{~h}$

FIgURE 9: DSC thermograms of composites LDPE/treated Spartium junceum flour at $25^{\circ} \mathrm{C}(70 / 30)$.

composites LDPE/SJ compared to composites with untreated flour. Also, the values of these parameters for the composites with the SJ flour treated at the temperature of $25^{\circ} \mathrm{C}$ are higher than those of the composites with the SJ flour treated at $40^{\circ} \mathrm{C}$.

A decrease in the melt flow index with the increase of the flour content is noticed. But, a slight improvement of the values of the composites MFT is observed with the treatment.

The incorporation of SJ flour to LDPE has no significant impact on the melting temperature but increases the crystallinity.

\section{References}

[1] Y. Lei, Q. Wu, and F. Yao et Y. Xu, "Préparation et propriétés de PEHD recyclé/Composites fibres naturelles," Composites Part A, vol. 38, no. 7, pp. 1664-1674, 2007.

[2] A. K. Bledzki and J. Gassan, "Composites reinforced with cellulose based fibres," Progress in Polymer Science, vol. 24, no. 2, pp. 221-274, 1999.

[3] A. C. Milanese, M. O. H. Cioffi, and H. J. C. Voorwald, "Mechanical behavior of natural fiber composites," Procedia Engineering, vol. 10, pp. 2022-2027, 2011. 
[4] D. Pasquini, E. D. M. Teixeira, A. A. D. S. Curvelo, M. N. Belgacem, and A. Dufresne, "Surface esterification of cellulose fibres: processing and characterisation of low-density polyethylene/cellulose fibres composites," Composites Science and Technology, vol. 68, no. 1, pp. 193-201, 2008.

[5] F. G. Torres and M. L. Cubillas, "Study of the interfacial properties of natural fibre reinforced polyethylene," Polymer Testing, vol. 24, no. 6, pp. 694-698, 2005.

[6] M. Zampaloni, F. Pourboghrat, S. A. Yankovich et al., "Kenaf natural fiber reinforced polypropylene composites: adiscussion on manufacturing problems and solutions," Composites Part A, vol. 38, no. 6, pp. 1569-1580, 2007.

[7] Z. Dominkovics, L. Dányádi, and B. Pukánszky, "Surface modification of wood flour and its effect on the properties of PP/wood composites," Composites Part A, vol. 38, no. 8, pp. 1893-1901, 2007.

[8] M. Bengtsson, M. L. Baillif, and K. Oksman, "Extrusion and mechanical properties of highly filled cellulose fibrepolypropylene composites," Composites Part A, vol. 38, no. 8, pp. 1922-1931, 2007.

[9] G. Gong, B. H. Xie, M. B. Yang, W. Yang, W. Q. Zhang, and M. Zhao, "Mechanical properties and fracture behavior of injection and compression molded polypropylene/coal gangue powder composites with and without a polymeric coupling agent," Composites Part A, vol. 38, no. 7, pp. 1683-1693, 2007.

[10] V. O. Guffey and A. B. Sabbagh, "PVC/wood-flour composites compatibilized with chlorinated polyethylene," Journal of Vinyl and Additive Technology, vol. 8, no. 4, pp. 259-263, 2002.

[11] S. Mishra and J. B. Naik, "Effect of treatment of maleic anhydride on mechanical properties of natural fiber: polystyrene composites," Polymer. Plastics Technology and Engineering, vol. 44, no. 4, pp. 663-675, 2005.

[12] S. Nekkaa, N. Haddaoui, A. C. Grillet, and G. Merle, "Thermal, thermomechanical, and morphological properties of spartium junceum fiber reinforced polypropylene composites," International Journal of Polymeric Materials, vol. 55, no. 11, pp. 837-853, 2006.

[13] S. Nekkaa, M. Guessoum, and N. Haddaoui, "Water absorption behavior and impact properties of spartium junceum fiber composites," International Journal of Polymeric Materials, vol. 58, no. 9, pp. 468-481, 2009.

[14] K. Sirisinha and D. Meksawat, "Comparison in processability and mechanical and thermal properties of ethylene-octene copolymer crosslinked by different techniques," Journal of Applied Polymer Science, vol. 93, no. 3, pp. 1179-1185, 2004.

[15] A. C. H. Barreto, D. S. Rosa, P. B. A. Fechine, and S. E. Mazzetto, "Properties of sisal fibers treated by alkali solution and their application into cardanol-based biocomposites," Composites Part A, vol. 42, no. 5, pp. 492-500, 2011.

[16] S. K. Madhuban, S. K. Bhaduri, S. K. Banerjee, and K. P. Sao, "Acetylation of jute and infrared spectra of acetylated jute," Indian Journal of Textile Research, vol. 10, no. 68, pp. 68-70, 1985.

[17] F. Corrales, F. Vilaseca, M. Llop, J. Gironès, J. A. Méndez, and P. Mutjè, "Chemical modification of jute fibers for the production of green-composites," Journal of Hazardous Materials, vol. 144, no. 3, pp. 730-735, 2007.

[18] X. Colom, F. Carrasco, P. Pagès, and J. Canavate, "Effects of different treatments on the interface of HDPE/lignocellulosic fiber composites," Composites Science and Technology, vol. 63, no. 2, pp. 161-169, 2003.
[19] P. W. Balasuriya, L. Ye, and Y. W. Mai, "Mechanical properties of wood flake-polyethylene composites. Part I: Effects of processing methods and matrix melt flow behaviour," Composites Part A, vol. 32, no. 5, pp. 619-629, 2001.

[20] K. Oksman and C. Clemons, "Mechanical properties and morphology of impact modified polypropylene-wood flour composites," Journal of Applied Polymer Science, vol. 67, no. 9, pp. 1503-1513, 1998.

[21] E. T. N. Bisanda and M. P. Ansell, "The effect of silane treatment on the mechanical and physical properties of sisalepoxy composites," Composites Science and Technology, vol. 41, no. 2, pp. 165-178, 1991.

[22] Y. Habibi, W. K. El-Zawawy, M. M. Ibrahim, and A. Dufresne, "Processing and characterization of reinforced polyethylene composites made with lignocellulosic fibers from Egyptian agro-industrial residues," Composites Science and Technology, vol. 68, no. 7-8, pp. 1877-1885, 2008.

[23] A. K. Mohanty, M. A. Khan, and G. Hinrichsen, "Surface modification of jute and its influence on performance of biodegradable jute-fabric/Biopol composites," Composites Science and Technology, vol. 60, no. 7, pp. 1115-1124, 2000.

[24] S. M. B. Nachtigall, G. S. Cerveira, and S. M. L. Rosa, "New polymeric-coupling agent for polypropylene/woodflour composites," Polymer Testing, vol. 26, no. 5, pp. 619-628, 2007.

[25] L. Dányádi, T. Janecska, Z. Szabó, G. Nagy, J. Móczó, and B. Pukánszky, "Wood flour filled PP composites: compatibilization and adhesion," Composites Science and Technology, vol. 67, no. 13, pp. 2838-2846, 2007.

[26] A. Bendahou, Y. Habibi, H. Kaddami, and A. Dufresne, "Composite materials based on ligno-cellulosic fibres and thermoplastic matrices (IPP and LDPE)," Revue Roumaine de Chimie, vol. 54, no. 7, pp. 557-563, 2009.

[27] L. Avérous, C. Fringant, and L. Moro, "Plasticized starchcellulose interactions in polysaccharide composites," Polymer, vol. 42, no. 15, pp. 6565-6572, 2001.

[28] F. Le Digabel, N. Boquillon, P. Dole, B. Monties, and L. Averous, "Properties of thermoplastic composites based on wheat-straw lignocellulosic fillers," Journal of Applied Polymer Science, vol. 93, no. 1, pp. 428-436, 2004.

[29] P. V. Joseph, K. Joseph, S. Thomas et al., "The thermal and crystallisation studies of short sisal fibre reinforced polypropylene composites," Composites Part A, vol. 34, no. 3, pp. 253-266, 2003.

[30] S. Nekkaa, M. Guessoum, F. Chebira, and N. Haddaoui, "Effect of fiber content and chemical treatment on the thermal properties of spartium junceum fiber-reinforced polypropylene composites," International Journal of Polymeric Materials, vol. 57, no. 8, pp. 771-784, 2008. 

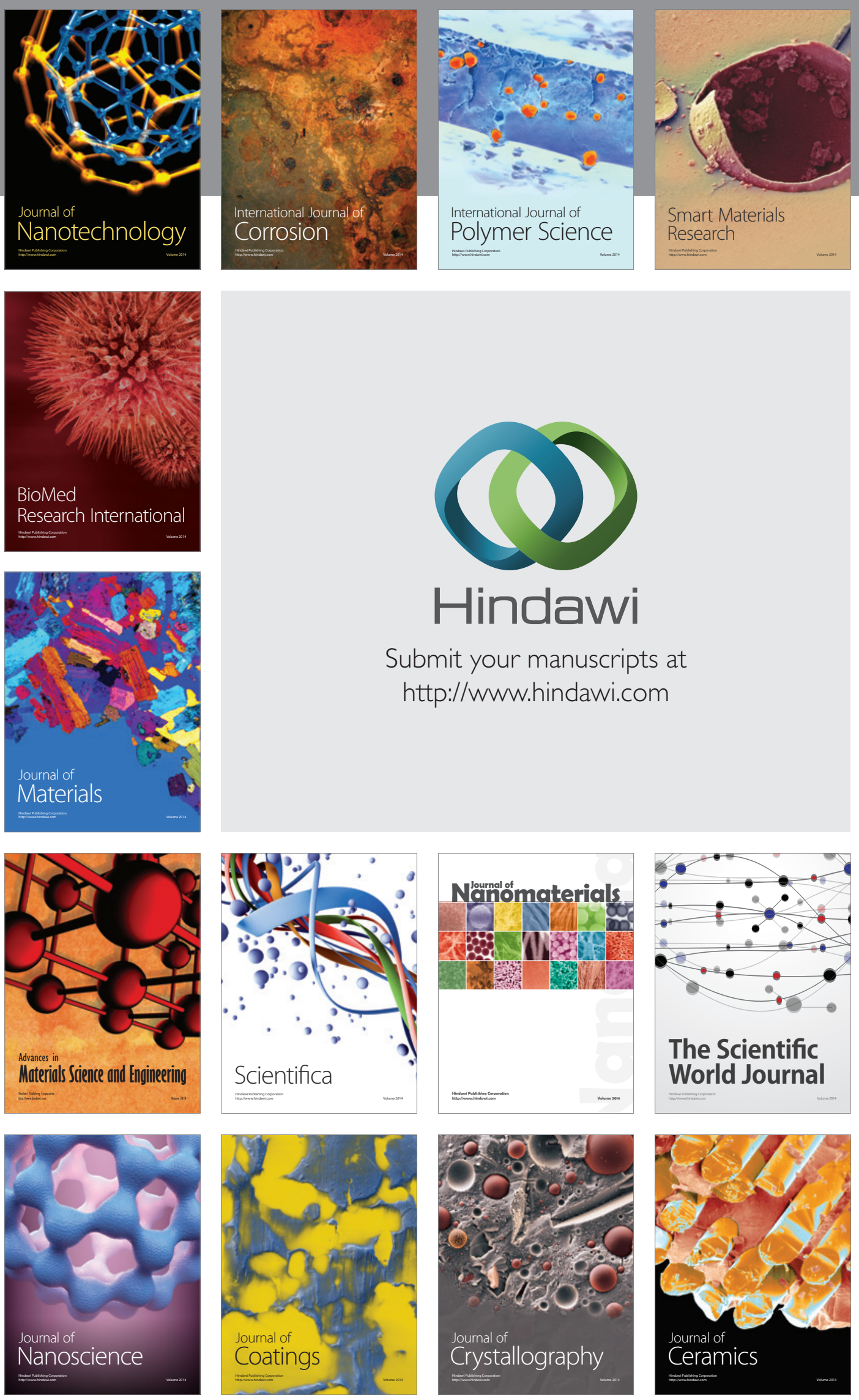

The Scientific World Journal

Submit your manuscripts at

http://www.hindawi.com

\section{World Journal}

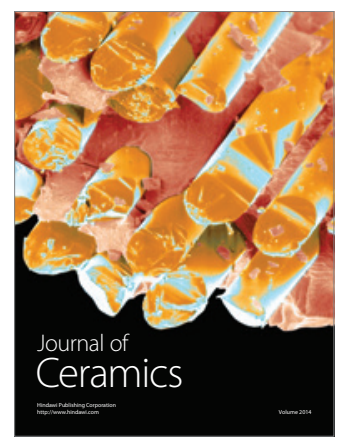

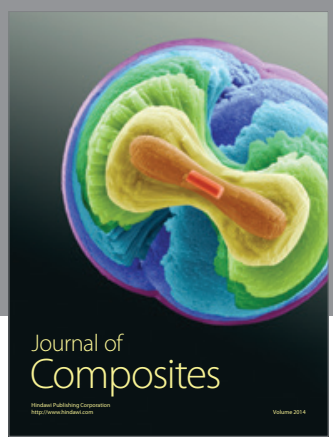
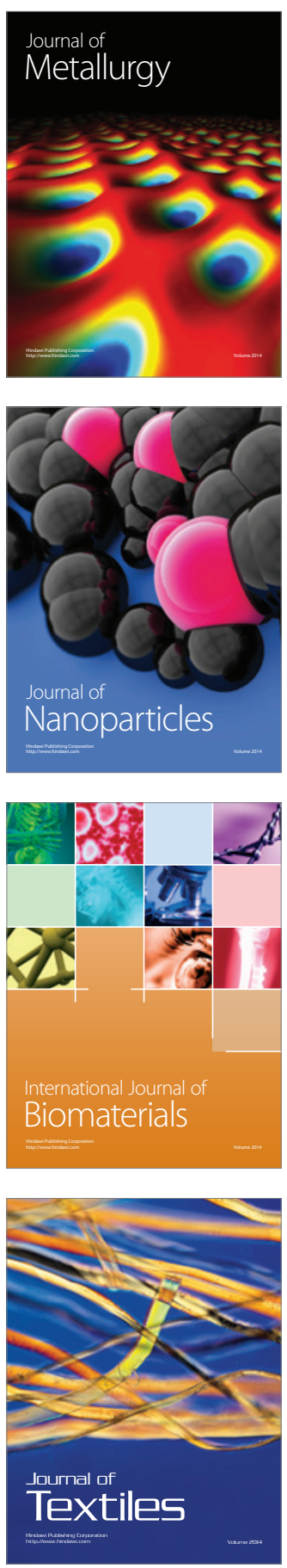